\title{
Information-Seeking Behavior of Multicultural Students: A Case Study at San Jose State University
}

\author{
Mengxiong Liu and Bernice Redfern
}

In 1995 a survey was conducted on the campus of San Jose State University where, for the first time, so-called minorities made up 50.7 percent of the total student population. Asian students compose the largest group among other ethnic groups. The study shows that students who use English as their primary language are usually more successful in using the library than those who use English as a second language. Length of stay in the United States also affects how often students use the library, as well as their behavior in asking reference questions. The survey found that Asian students are hindered by a fear of asking stupid questions, a belief that their English is not good enough, an inability to understand answers well, and a lack of familiarity with the library reference desk.

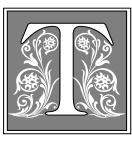

he demographics of the U.S. population are changing. Our society is becoming more culturally diverse, with greater minority composition. Statistical projections indicate that the percentage of minorities will grow significantly in this decade. Likewise, the population of college campuses has become more diverse in recent years. At San Jose State University, the total minority enrollment has grown from 10,353 in the fall of 1988 to 13,169 in the fall of 1995. For the first time, the so-called minorities make up 50.7 percent of the total student population. Asians comprise 25.49 percent of this group, followed by Hispanics who make up 13.22 percent. Filipinos, African Americans, Native Ameri- cans, and Pacific Islanders form even smaller percentages. ${ }^{1}$

How do college and university libraries respond to the needs of a more diversified student body? How do librarians provide more effective and efficient services to their multicultural patrons? Knowing the information needs and information-seeking behavior of library users from culturally diverse populations not only helps explain the multicultural communication process, but also aids librarians in developing systems and services to meet the increasing challenge of a diversified society.

\section{Background and Related Research}

Currently, there is great interest in higher education-and among academic librar-

Mengxiong Liu is a Reference Librarian in Clark Library at San Jose State University; e-mail: mengxion@sjsuvm1.sjsu.edu. Bernice Redfern is a Reference Librarian in Clark Library at San Jose State University; e-mail: redfern@sjsuvm1.sjsu.edu. 
ians-in addressing the needs of multicultural students. Several studies published in recent years advocate the need for special programs and services for multicultural students in academic libraries. In a 1990 article, Glaviano and Lam discussed the importance of affirmative action strategies in academic libraries and stressed the value of greater cultural diversity within the academic library. ${ }^{2}$

\section{By obtaining insight into how university students of various ethnic groups use libraries, academic librarians may be better able to respond to the specific needs of multicultural students.}

Trujillo and Weber examined the academic library's response to cultural diversity and suggested steps that can be taken to improve its response. ${ }^{3}$ In addition, the implications of the pluralistic campus in the year 2000 are addressed in an article by Welch and Lam. ${ }^{4}$ Chadley surveyed directors of ARL libraries to investigate their interest in cultural diversity. Results indicate that research libraries are making progress in creating a culturally diverse climate. ${ }^{5}$ In a survey of two hundred academic library directors in areas of large ethnic populations, Buttlar found that 92 percent of the directors have appropriated financial resources to facilitate cultural diversity. ${ }^{6}$ These studies provide excellent overviews of the response of academic libraries to multiculturalism.

International students form a component of the ethnically diverse student population. A number of recent studies discuss the need to provide special services for this growing segment of the student population. Allen surveyed the characteristics of the international student population in order to determine patterns of library use. She concluded that libraries may need to make special efforts to provide instructional services to these stu- dents. ${ }^{7}$ Moreover, a study by SarkodieMensah suggests that academic librarians should become more aware of pronunciation differences, more attuned to meanings, and more tactful and sensitive to differing cultural perspectives when assisting international students. ${ }^{8}$

Liu examined the difficulties of students from developing countries, mostly Asian students, in using American libraries. In an interview conducted with students studying at the University of California-Berkeley, she found that students in natural sciences have fewer difficulties than those in humanities and social sciences. Also, those students who are proficient in English and whose home countries are strongly influenced by American culture encounter fewer difficulties. ${ }^{9}$

The present study responds to the need for research on information-seeking patterns among multicultural students. By obtaining insight into how university students of various ethnic groups use libraries, academic librarians may be better able to respond to the specific needs of multicultural students.

\section{Goal of the Study}

The goal of this study is to obtain insight into how university students from diverse ethnic groups discover, select, and use information and communication resources. The study investigates various information channels students use. It also examines communication patterns among a diverse student population. More specifically, it identifies the cultural and educational background of the students and the impact these factors have on their information-seeking behavior.

\section{Methodology}

The authors used an exploratory survey method, or experience survey to be more specific, in this study. ${ }^{10}$ The purpose of this type of survey was to obtain insights into the relationships between user behavior and the reasons behind it in the studied groups, rather than to generalize 
the findings to the whole campus. The authors' primary interest was in gaining some provocative ideas, useful insights, and suggestions for future research. Because this was a preliminary study, exploratory in nature, a high-response rate was important in order to generate necessary information for further research. Therefore, the authors decided to give the questionnaires to faculty members who agreed to distribute them in their classes. The cover letter made it clear to the students that participation in the study was voluntary, and that choosing not to participate would not affect their academic attainments. The authors also made sure that faculty assured their students that completion of the questionnaire was not part of their class assignment. The returned questionnaires were anonymous. Out of the 300 distributed questionnaires, $237(79 \%)$ were returned.

The questionnaire was designed to measure the composition of the student body in the surveyed classes at San Jose State University; to investigate the students' experience of using the library, such as visit frequency, purpose of visit, and difficulty and success level; and to examine whether the students asked librarians for assistance, as well as the reasons for the request. The assumption was that students with multicultural backgrounds may have different informationseeking behaviors which could result in different success levels in using the library.

Statistical analyses were performed cautiously with the exploratory data. However, no causal relationship could be generalized but, rather, applied only to the particular cases that were studied.

\section{Findings}

\section{Profile of the Students}

Among the 237 respondents, 57.8 percent were male and 42.2 percent were female. In the area of ethnic composition, 62 percent were Asian and 27 percent said they were Caucasian. Six percent were listed as other, four percent as Hispanic, and one percent as African American.

Fifty-eight percent indicated that country of origin was an Asian country; 31 percent said that their country of origin was the United States; and four percent listed country of origin as a Middle Eastern country. Latin America and Europe each was listed as country of origin by six percent of the respondents, whereas one percent listed Africa as place of origin.

Sixty percent of the study respondents said that English was their second language, compared to 40 percent who indicated that English was their primary language. Sixty percent of those surveyed said they had lived in the United States between five and fifteen years, whereas 32 percent indicated they had lived in this country for less than five years. Seven percent said they had lived here between sixteen and twenty years, and one percent between twenty-one and twenty-five years.

Most of the Asian students who completed the questionnaire indicated their major was engineering (44\%), compared to 30 percent of the Caucasian students.

\section{Fifty-eight percent indicated that country of origin was Asian.}

This profile indicates that San Jose State University is a very ethnically diverse, metropolitan university.

\section{Success Level of Library Use}

In general, the students used the library quite often (more than $40 \%$ said they often used the library). They indicated that they had little difficulty in using the library; in fact, 60 percent of these students said using the library was easy. They also found themselves quite successful (45\%) in finding the information they needed in the library.

Statistical analyses did not find gender, discipline, or country of origin to be related to students' library use behavior. However, the authors did find that the stu- 


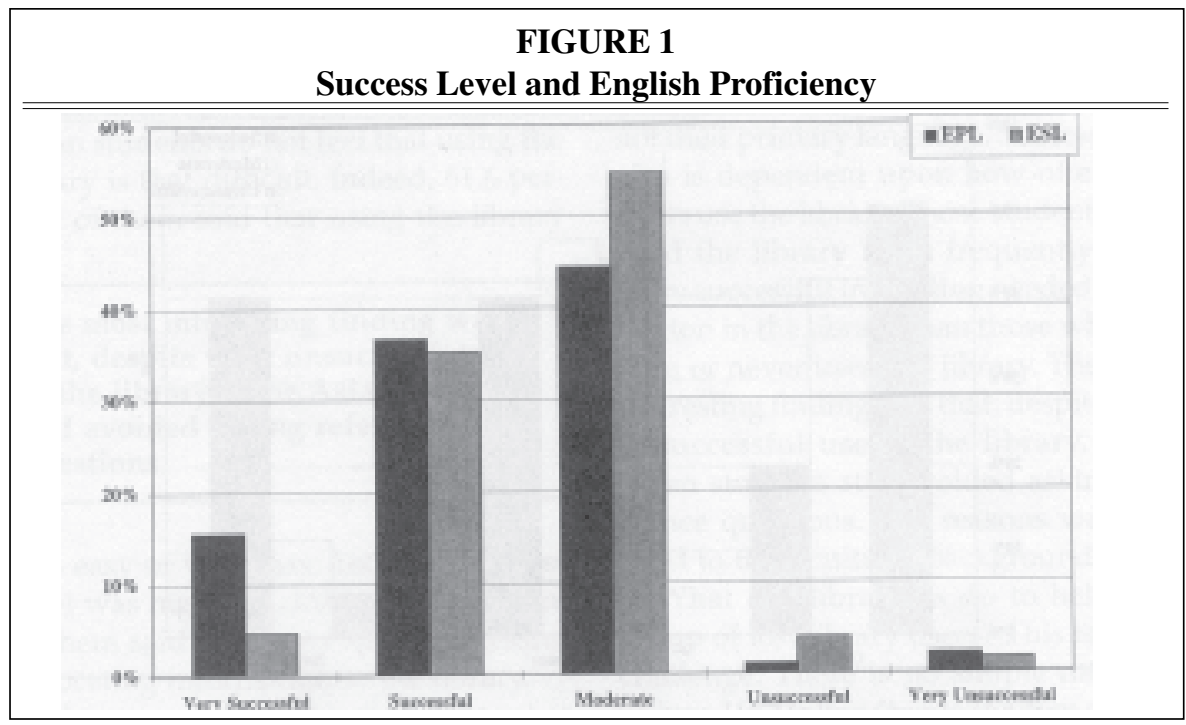

dents' level of success in using the library is related to these factors: English proficiency, frequency of library use, and frequency of reference desk inquiry. The chisquare tests showed a .05 level of statistical significance among these variables.

\section{Success Level and English Proficiency}

The bar chart in figure 1 shows that students with English as their primary language, whether native born or from an English-speaking country, are usually more successful in using the library than those whose English is not their primary language. The biggest difference between the two groups is the level of "very successful." Whereas 15.6 percent of the students who speak English as their primary language were very successful in using the library, only 4.7 percent of the nonnative English speakers checked "very successful" in their use of the library. Therefore, English language proficiency makes a difference in the success level of students' use of the library.

\section{Success Level and Frequency of Library Use}

Success level also is dependent upon how often students use the library (see figure 2 ). The authors found that those students who used the library more frequently were more successful in locating needed information, whereas those who seldom used the library felt they were often unsuccessful.

Further analysis shows that the length of stay in the United States makes a difference in the frequency of students' library use. Students who have been in the country for more than sixteen years tend to use the library more frequently than those who have been in the country for less than fifteen years. Apparently, length of stay plays a part in the students' level of information-seeking success.

\section{Success Level and Reference Inquiry}

In addition, students' success levels could depend upon whether they ask reference questions. The chart in figure 3 shows that those students who ask reference questions more frequently are likely to be more successful in locating needed information in the library. A majority $(61.2 \%)$ of frequent reference inquirers felt they were quite successful in finding needed information.

The authors also found that length of stay in this country was a factor that affects students' behavior in asking reference questions. Students who have stayed in this country for more than sixteen years 


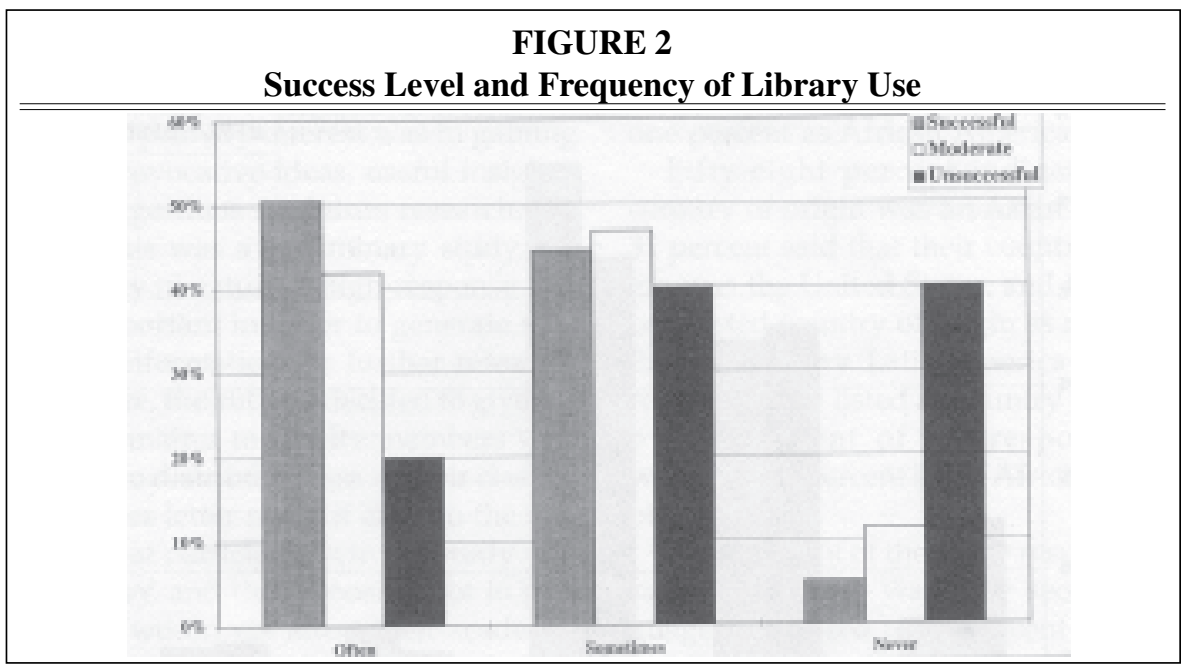

ask reference questions more frequently than those who have been here for less than fifteen years.

It can be speculated that length of stay determines the degree to which students from foreign countries feel adapted to the society and, therefore, comfortable with using libraries and asking reference questions. A period of adaptation may take as long as fifteen years. It leads to the assumption that a person's informationseeking behavior may change after stay- ing in a different culture for a certain period of time.

\section{Asian Students: Difficulty and Success}

Because Asian students comprised the majority of the surveyed student group, and also represent the largest ethnic group on campus, separate statistics were performed to analyze their library use pattern. The authors found that most Asian students do not feel that using the library is that difficult. Indeed, 61.6 per-

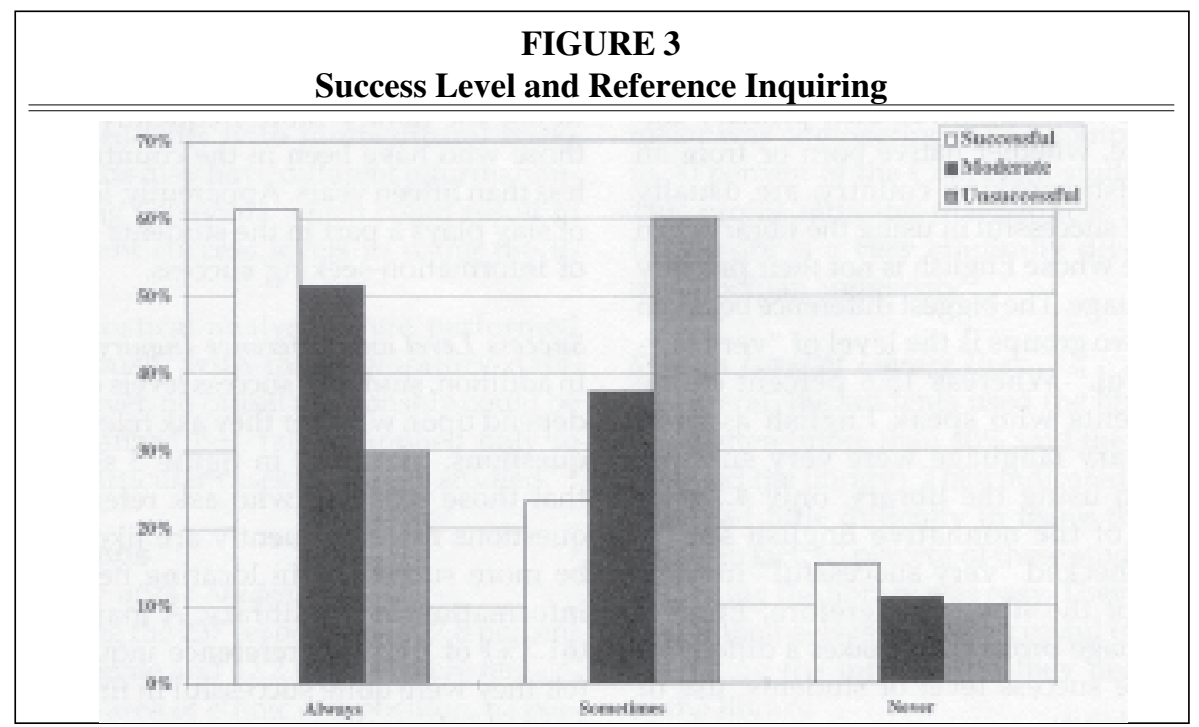


cent of them said that using the library was easy or very easy, and their success level was high. In addition, 44.3 percent of them said they were quite successful in locating information in the library.

The most interesting finding was that, despite their unsuccessful use of the library, some Asian students still avoided asking reference questions.

However, among those who were not that successful and those who seldom asked reference questions, the following reasons contributed to their behavior of avoiding the reference desk:

- afraid of asking stupid questions;

- afraid of English not being good enough;

- afraid of not understanding answers well;

- never think of asking reference questions;

- do not know what a reference librarian does.

\section{Conclusions and Recommendations}

The analysis presented here describes how students from diverse ethnic backgrounds attending a large metropolitan university use information resources. A survey was used to examine the level of success and the level of difficulty of their library use. It was found that students with English as their primary language usually were more successful in using the library than those for whom English is not their primary language. Success level also is dependent upon how often students use the library. Those students who used the library more frequently were more successful in locating needed information in the library than those who seldom or never used the library. The most interesting finding was that, despite their unsuccessful use of the library, some Asian students still avoided asking reference questions. The reasons were related to their cultural background.

What can librarians do to help this group of lost library users? This is a real challenge. There is no simple menu to follow. Understanding is the first step in approaching the problem. Developing skill in intercultural communication is the second step. The third step is to make explanations relative rather than absolute. Finally, all explanations about the problem should be made relevant to students' "lifeworld." 11

Cultural diversity is a reality today. If librarians do not make an effort to study their more ethnically diverse patrons, misperceptions about these groups and their information needs will remain. To benefit from the ideas and perspectives of different cultures, academic libraries must become more active in developing and strenthening library services for multicultural students. They must provide a welcoming environment for students from diverse cultures. Most of all, they must encourage these students to make use of the campus library and its services.

\section{Notes}

1. These figures are from the Office of Institutional Research, San Jose State University.

2. Cliff Glaviano and R. Errol Lam, "Academic Libraries and Affirmative Action: Approaching Cultural Diversity in the 1990s," College and Research Libraries 51 (Nov. 1990): 513-23.

3. Roberto G. Trujillo and David C. Weber, "Academic Library Responses to Cultural Diversity: A Position Paper for the 1990s," Journal of Academic Librarianship 17 (July 1991): 157-61.

4. Janet E. Welch and R. Errol Lam, "The Library and the Pluralistic Campus in the Year 2000: Implications for Administrators," Library Administration and Management 5 (fall 1991): 21216.

5. Otis A. Chadley, "Addressing Cultural Diversity in Academic and Research Libraries," College and Research Libraries 53 (May 1992): 206-14.

6. Lois Buttlar, "Facilitating Cultural Diversity in College and University Libraries," Journal 
of Academic Librarianship 20 (March 1994): 10-14.

7. Mary Beth Allen, "International Students in Academic Libraries: A User Survey," College and Research Libraries 54 (July 1993): 323-33.

8. Kwasi Sarkodie-Mensah, "Dealing with International Students in a Multicultural Era," Journal of Academic Librarianship 18 (Sept. 1992): 214-16.

9. Ziming Liu, "Difficulties and Characteristics of Students from Developing Countries in Using American Libraries," College and Research Libraries 54 (Jan. 1993): 25-31.

10. Ronald R. Powell, Basic Research Methods for Librarians (Norwood, N.J.: Ablex Pub., 1991), 54-55.

11. Mengxiong Liu, "Library Services for Ethnolinguistic Students," Journal of Educational Media and Library Sciences 32 (spring 1995): 129-246. 